\title{
Persistence of microbial and chemical pig manure markers as compared to faecal indicator bacteria survival in freshwater and seawater microcosms
}

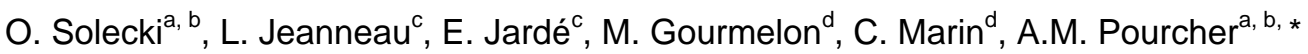 \\ ${ }^{a}$ Cemagref, 17, avenue de Cucillé, 35044 Rennes cedex, France \\ ${ }^{\mathrm{b}}$ Université Européenne de Bretagne, France \\ ${ }^{\mathrm{c}}$ CNRS UMR 6118 Géosciences Rennes, France \\ ${ }^{\mathrm{d}}$ Ifremer, EMP, Laboratoire de Microbiologie, Plouzané, France \\ *: Corresponding author : Anne-Marie Pourcher, email address : anne-marie.pourcher@cemagref.fr
}

\begin{abstract}
:
Natural seawater and freshwater microcosms inoculated with pig manure were set up to determine the persistence of pig faecal microbial and chemical markers in these two types of surface water. The concentrations of Lactobacillus amylovorus, the Bacteroidales Pig-2-Bac 16S rRNA genetic marker, five stanols and the evolution of two ratios of stanols, $R_{1}$ (coprostanol to the sum of coprostanol and 24-ethylcoprostanol) and $R_{2}$ (sitostanol to coprostanol) were analyzed during two months along with the concentration of Faecal Indicator Bacteria (FIB). Pig manure was inoculated to unfiltered water microcosms incubated aerobically at $18{ }^{\circ} \mathrm{C}$ in the dark. The faecal contamination load represented by the concentrations of culturable Escherichia coli and/or enterococci remained for two months in the freshwater and seawater microcosms water column. These concentrations followed a biphasic decay pattern with a $97 \%$ reduction of the initial amount during a first rapid phase ( $<6$ days) and a remaining proportion undergoing a slower or null second decline. The L. amylovorus marker and five stanols persisted as long as the indicators in both treatments. The Pig-2-Bac marker persisted 20 and 27 days in seawater and freshwater, respectively. The ratios $R_{1}$ and $R_{2}$ were in the range specific to pig manure until day 6 in both types of water. These results indicate that Pig-2-Bac, L. amylovorus and stanol ratios might be used in combination to complement FIB testing to determine the pig source of fecal pollution. However, stanol ratios are to be used when the time point of the discharge is known.
\end{abstract}

\section{Highlights}

Escherichia coli and enterococci from pig manure followed a biphasic decay in water microcosms.

The marker Lactobacillus amylovorus followed the same trend as enterococci in fresh and seawater. The marker Pig-2-Bac followed the same trend as E. coli in seawater. Pig-specific stanols and $L$. amylovorus persisted for two months. Stanols and $L$. amylovorus detection and persistence was not affected by salinity.

Keywords : Faecal source tracking; Decay rates; Faecal stanols; Biphasic kinetic; Lactobacillus amylovorus; Bacteroidales marker 


\section{Introduction}

Each year, the microbial analyses of the 540 freshwater and seawater bathing areas located in Brittany, North West of France, reveal that these areas might be sporadically contaminated by high faecal loads. Among the three main sources of faecal contamination (human, pig and cow) which can lead to the downgrading of these areas (Soller et al., 2010), pig manure spreading is considered as a potential factor of water pollution (Thurston-Enriquez et al., 2005). Brittany supports more than half of the national pigs' livestock while representing only $5 \%$ of the French territory and this high concentration generates from 8 to 10 million tons of pig manure each year. To protect public health whilst bathing and to improve management practices at bathing waters, the revised Bathing Water European Directive (2006/7/EC) requires to establish bathing water profiles to identify the source(s) of a faecal pollution upstream a targeted water body.

To track pollution to livestock facilities or diffuse non point sources, animal-specific markers have been proposed. They include DNA molecules from intestinal bacteria (Dick et al., 2005; Ufnar et al., 2007), endogenous eukaryotic cells (Balleste et al., 2010) and faecal stanols (Tyagi et al., 2009). Among pig genetic markers, studies have focused essentially on bacteria from the Bacteroidales order as potential markers preferred for their abundance in the gastrointestinal tract and host specificity occurrence (Dick et al., 2005; Mieszkin et al., 2009). Among chemical markers, faecal stanols are considered as direct markers because they occur in the faeces (Leeming et al., 1996). The distribution of those compounds in animal faeces depends on three host factors: (i) the animal's diet, (ii) the ability to biosynthesize 
endogenous sterols and (iii) the occurrence of anaerobic bacteria able to biohydrogenate sterols to stanols of various isomeric configurations. The combination of those three factors determines the "sterol fingerprint" that is characteristic of each animal faeces (Leeming et al., 1996).

In a previous study from our teams, several microbial and chemical markers detected in river waters impacted by faecal pollutions were proposed to be used in a toolbox as Faecal Source Tracking methods (FST) (Gourmelon et al., 2010). Two of which were microbial pig-specific markers previously validated for their host specificity, the genetic Bacteroidales marker Pig2-Bac and the bacterial species Lactobacillus amylovorus (Marti et al., 2010; Mieszkin et al., 2009). Five faecal stanols found in pig faeces and two steroids ratios were also selected to be part of the toolbox. Specific markers should exhibit high host-specificity and represent the load of faecal pollution (Field and Samadpour, 2007). In this scope, the evaluation of markers to be used as FST must consider whether the degradation and transport characteristics of the markers are similar to that of one or several pathogens or to the traditional faecal indicator bacteria (FIB) such as Escherichia coli (E. coli) and enterococci.

The present study examines the detection of Pig-2-Bac marker, L. amylovorus and faecal stanols as compared to the detection of FIB in natural surface water microcosm. The faecal

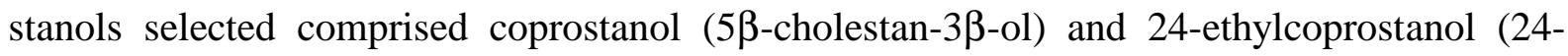

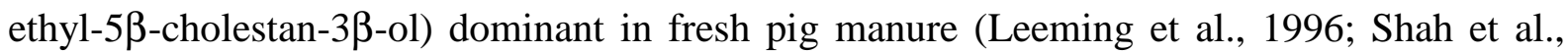

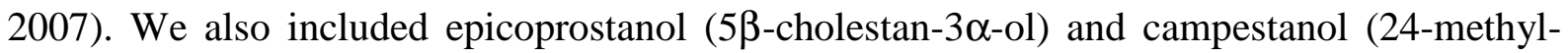
$5 \alpha$-cholestan-3 $\beta$-ol) since the land spreading of pig manure as a soil fertilizer results in high concentration of those compounds (Jarde et al., 2009). Two ratios of concentrations of steroids were calculated along the experiment: coprostanol to the sum of coprostanol and 24ethylcoprostanol $\left(\mathrm{R}_{1}\right)$ and sitostanol to coprostanol $\left(\mathrm{R}_{2}\right)$. In the previous study to this work, pig manure was characterized by a $R_{1}$ ratio of $0.57 \pm 0.02$ and a $R_{2}$ ratio of $0.3 \pm 0.1$ 
80 The objective of this study was to estimate the persistence and decay rates of pig genetic

81 markers, faecal stanols, and FIB in fresh and marine water during two months. The evaluation

82 to which extent the detection of tested markers and ratios correlates with that of FIB and

83 hence, represents faecal load contamination should allow to validate their usefulness as

84 markers of pig faecal pollution in these two types of surface water.

85

86 2. MATERIALS AND METHODS

87 2.1. Microcosms design

88 Microcosms consisted of 6 one hundred-litres inert glass aquariums placed in a dark room,

89 protected from sunlight and fluctuating temperature. Three of which were filled with seawater

90 and the remaining aquariums with freshwater. Both waters were not filtered to study the

91 persistence of FIB and specific markers in presence of protozoa. Waters were seeded with pig

92 liquid manure. Constant mixing was achieved with the aid of a helix agitator and oxygen

93 saturation with air pumped in throughout the experiment. A plastic film cover limited

94 evaporation of water. The type of surface water was the changing parameter. Ambient

95 temperature (around $18{ }^{\circ} \mathrm{C}$ ) corresponded with surface water temperature during the warmer

96 months in Brittany (France). Nine hundred $\mathrm{mL}$ of untreated liquid pig manure was added to

$9790 \mathrm{~L}$ of water (1:100 dilution). This ratio was chosen to represent a high faecal load

98 contamination likely to remain for two months. However, the turbidity resulting from this

99 parameter hindered light treatment.

100 Sampling took place on the starting day, then on day 2, 6, 13, 20, 27, 34, 41, 48 and 55. Both

101 unseeded initial types of water were kept in the same conditions during the whole experiment

102 to use as controls, sampling took place on the starting day and on day 55. Culturable E. coli

103 (cEC), culturable enterococci (cENT), bacterial genetic markers and stanol concentrations

104 were measured at each sampling point. Dissolved $\mathrm{O}_{2}$ concentration and temperature were

105 measured every 3 to 4 days. Although constant mixing was achieved in the middle of the 
aquarium, sedimentation occurred during the course of the experiment and biofilms formation

107 occurred on the walls. Samples were drawn from the water column.

109 2.2. Water and pig manure samples

110 The seawater was collected in the end of January 2010 in the Atlantic Ocean from Landunvez,

111 in the NW Brittany region of France (lat $\times$ long: $48.540819 \times-4.751587$ ). Salinity was $33 \mathrm{~g} / \mathrm{L}$,

112 total dissolved organic carbon measurement was $0.4 \mathrm{mg} \mathrm{C} / \mathrm{L}$, total dissolved nitrogen was 4.0

$113 \mathrm{mg} \mathrm{N} / \mathrm{L}$. The freshwater was sampled from a lake in Commana in Brittany (lat $\times$ long:

$11448.3887488 \times-4.0177564)$ on the same day, the total dissolved organic carbon was $2.7 \mathrm{mg}$

$115 \mathrm{C} / \mathrm{L}$, the total dissolved nitrogen was $9.3 \mathrm{mg} \mathrm{N} / \mathrm{L}$. Pig manure was collected from a farm

116 located in Brittany and samples were taken from a storage tank after homogenisation with

117 propeller agitator for 20 minutes, the total dissolved carbon and total dissolved nitrogen were

$118 \quad 6.5 \mathrm{~g} \mathrm{C} / \mathrm{L}$, and $2.9 \mathrm{~g} \mathrm{~N} / \mathrm{L}$, respectively.

\subsection{Enumeration of FIB}

121 Depending on sample turbidity, FIB counts were achieved either by serial dilution in buffered peptoned water (Oxoid, Basingstoke, England) or by filtration of $100 \mathrm{~mL}$ of sample on a 0.45 $\mu \mathrm{m}$ cellulose membrane (Whatman, Dassel, Germany). Filters or $0.1 \mathrm{~mL}$ of the dilution was plated on TBX agar (Oxoid) and on Slanetz and Bartley agar (Biokar Diagnostics, Beauvais,

125 France). TBX plates were incubated for $24 \mathrm{~h}$ at $44{ }^{\circ} \mathrm{C}$. Blue colonies (glucuronidase positive)

126 were counted to determine the concentration of E. coli. After incubation at $37{ }^{\circ} \mathrm{C}$ for $48 \mathrm{~h}$, 127 membranes on Slanetz and Bartley agar were transferred onto Bile-Esculin-Azide agar (BEA)

128 (Biokar Diagnostics) and incubated for $2 \mathrm{~h}$ at $44{ }^{\circ} \mathrm{C}$. Black colonies on BEA were counted as 129 enterococci. The detection limit of both methods was 1 colony forming units (CFU) per 100 $130 \mathrm{~mL}$. 


\subsection{Microbial markers analyses}

\section{2.4.1. Samples preparation and DNA extraction}

134 Two hundreds $\mathrm{mL}$ of samples were either centrifuged (9000 $\mathrm{g}$ for $15 \mathrm{~min}$ ) or filtered onto 0.2

$135 \mu \mathrm{m}$ polycarbonate membrane (Sartorius, Goettingen, Germany) depending on suspended

136 matter density. Filtration was the preferred method to recover DNA. However, filtration was

137 not possible until day 13. On that day, samples from one microcosm of both types of water

138 were treated by both methods. Since qPCR results were similar, it was decided to carry on

139 with filtration. From 0.30 to $250 \mathrm{mg}$ of solid matter were recovered. DNA extraction was

140 performed on sample solid matter with the aid of the FastDNA® SPIN for Soil kit (MP

141 Biomedicals, Illkirch, France), following manufacturer's instructions. The elution volume was $142100 \mu \mathrm{L}$.

\subsubsection{Real-time PCR}

\subsubsection{Oligonucleotide primers and probes}

146 The pig-specific Bacteroidales 16S rRNA gene marker (Pig-2-Bac) and the L. amylovorus

147 marker were quantified with the primers and probe described by Mieszkin et al. (2009) and

148 Konstantinov et al. (2005), respectively.

\subsubsection{DNA standard curves}

150 For the quantification of the Bacteroidales marker Pig-2-Bac, standard curves were generated

151 from serial dilutions of known concentration of plasmid DNA ranging from $5 \times 10^{7}$ to $5 \times 10^{0}$

152 copies per reaction. Linear plasmids were extracted with the QIAquick Miniprep Extraction

153 Kit (Qiagen), following the manufacturer's instructions. The linear form of plasmid was 154 obtained with NotI enzyme (Roche Diagnostics, Meylan, France) in a final volume of $50 \mu \mathrm{L}$

155 for $3 \mathrm{~h}$ at $37^{\circ} \mathrm{C}$. The PCR standard curve for the L. amylovorus markers was prepared by 10156 fold dilution of bacterial genomic DNA extracted from one $\mathrm{mL}$ of a pure culture of $L$. 157 amylovorus DSM16698, with the Wizard genomic DNA purification Kit (Promega, Madison, 
158 USA) according to the manufacturer's instructions. Dilutions ranged from $4.5 \times 10^{6}$ to $4.5 \times$

$15910^{0} \mathrm{CFU}$ equivalent from direct plating count considering that $100 \%$ of the DNA from the

160 culture was recovered. Standard curves were generated by plotting threshold cycles $(\mathrm{Ct})$

161 against $16 \mathrm{~S}$ rRNA genes or CFU equivalent, depending on the marker. Standard curves were

162 obtained by means of 3 replicates per point.

163 2.4.2.3. Real-time PCR assays

164 For Pig-2-Bac marker, amplification was performed using the Chromo4 real-time detection 165 system associated with Bio-Rad Opticon Manager software version 3.1 (Bio-Rad, Hercules,

166 CA). Real-time PCR was performed using the TaqMan ${ }^{\circledR}$ Brilliant II QPCR Master Mix kit 167 (Agilent technologies, Massy, France). Each reaction was run in triplicate. The cycle 168 conditions were 1 cycle at $95{ }^{\circ} \mathrm{C}$ for $10 \mathrm{~min}$, followed by 40 cycles at $95{ }^{\circ} \mathrm{C}$ for $15 \mathrm{~s}$ and 60

$169{ }^{\circ} \mathrm{C}$ for $1 \mathrm{~min}$. Reactions were carried out in a final volume of $25 \mu \mathrm{L}$ with primers and probe

170 final concentration being $300 \mathrm{nM}$ and $200 \mathrm{nM}$ respectively. Quantification limit was 1250

171 16S rRNA gene copies per $100 \mathrm{~mL}$. The presence/absence of PCR inhibitors was verified

172 using an Internal Positive Control (IPC; AppliedBiosystem, France). Samples were diluted if 173 inhibitors were present.

174 Concerning the L. amylovorus marker, PCR was performed on the CFX96 real time system

175 (Bio-Rad), with the software Opticon Monitor version 3.1.32 and CFX manager version 1.1

176 (Bio-Rad), using the IQ SYBR-Green Supermix (Bio-Rad). The cycle conditions were 1 cycle 177 at $95{ }^{\circ} \mathrm{C}$ for $3 \mathrm{~min}$, followed by 40 cycles at $95{ }^{\circ} \mathrm{C}$ for $15 \mathrm{~s}$ and $60{ }^{\circ} \mathrm{C}$ for $45 \mathrm{~s}$. Reactions were 178 carried out in a final volume of $25 \mu \mathrm{L}$ with primers final concentration being $200 \mathrm{nM}$. 179 Quantification limit was $112.5 \mathrm{CFU}$ equivalents per $100 \mathrm{~mL}$.

180 No filtration, extraction and template positive controls from a known concentration of a 181 control DNA fragment were included in the method to evaluate the yield of DNA recovery.

\subsection{Faecal stanols analysis}


184 Five faecal stanols, namely coprostanol, epicoprostanol, 24-ethylcoprostanol, campestanol

185 and sitostanol were investigated in this study. Analyses were performed on $1 \mathrm{~L}$ of non seeded 186 initial waters and $500 \mathrm{~mL}$ of microcosm waters. Faecal stanols were extracted from the 187 dissolved phase $(<0.7 \mu \mathrm{m})$ by solid phase extraction and quantified by gas chromatography 188 mass spectrometry (GC-MS) according to the protocol developed by Jeanneau et al. (2011).

189 Cholesterol d6 (2,2,3,4,4,6- ${ }^{2} \mathrm{H}_{6}-5$-cholesten-3 $\beta$-ol $)$ was used as a recovery standard and was 190 added to water samples prior to the extraction step. $5 \alpha$-cholestane was used as an internal 191 standard and was added prior to the GC-MS analysis. Faecal stanols were quantified by the 192 internal standard method using a five-point calibration curve. The resulting calibration ranged 193 from 0.01 to $40 \mu \mathrm{g} / \mathrm{L}$ for stanols in water.

\subsection{Decay rate calculations}

196 The decay rates of faecal stanols were calculated based on a first order decay model (Chick 197 model):

$198 \mathrm{C}_{(\mathrm{t})}=\mathrm{C}_{0} \times \mathrm{e}^{-\mathrm{kt}}$ or $\ln \left(\mathrm{C}_{(\mathrm{t})} / \mathrm{C}_{0}\right)=-\mathrm{kt}$

199 Where $\mathrm{C}_{0}$ is the average initial concentration of the target in $\mu \mathrm{g} / \mathrm{L}, \mathrm{C}_{(\mathrm{t})}$ is the target average 200 concentration at time $\mathrm{t}$ in $\mu \mathrm{g} / \mathrm{L}, \mathrm{t}$ is the time in days and $k$ the decay constant or rate in days ${ }^{-1}$.

201 The model describes a linear regression, $k$ is the slope of the regression line and $R^{2}$ the 202 regression coefficient.

203 The biphasic model described by Lee et al. (2001) was used to calculate decay rates for every 204 microbial target in both treatments. Two constants were calculated from a biphasic first order 205 decay model (Cerf model):

$206 \mathrm{C}_{(\mathrm{t})}=\mathrm{C}_{0} \times\left(\mathrm{f} \times \mathrm{e}^{-\mathrm{k} 1 \mathrm{t}}+(1-\mathrm{f}) \times \mathrm{e}^{-\mathrm{k} 2 \mathrm{t}}\right)$ or $\ln \left(\mathrm{C}_{(\mathrm{t})} / \mathrm{C}_{0}\right)=\ln \left(\mathrm{f} \times \mathrm{e}^{-\mathrm{k} 1 \mathrm{t}}+(1-\mathrm{f}) \times \mathrm{e}^{-\mathrm{k} 2 \mathrm{t}}\right)$

207 Where $\mathrm{f}$ is the proportion of $\mathrm{C}_{0}$ that declined during the first phase, $k_{l}$ is the decay constant of 208 the first phase and $k_{2}$ the decay constant of the second phase. $\mathrm{C}_{(\mathrm{t})}$ and $\mathrm{C}_{0}$ are expressed in 209 CFU/100 mL for FIB, in CFU equivalent/100 mL for L. amylovorus and in DNA copies/100 
$210 \mathrm{~mL}$ for Pig-2-Bac. The biphasic model and associated parameters were obtained with the aid

211 of XLSTAT 2010.4 using the nonlinear regression modelling.

212 Decay rates were calculated until the day concentrations were below quantification limit or

213 until day 55 when the detection limit was not reached.

214 The length of time (expressed in days) needed to obtain a 90\% reduction in initial

215 concentration of stanols or bacteria was calculated as follows: $\mathrm{T}_{90}=-\ln (0.1) / k$ (Chick model)

216 or, if $\mathrm{f}$ was $>90 \%, \mathrm{~T}_{90}=-\ln (0.1) / k 1($ Cerf Model $)$

217

218

\subsection{Regression tests}

219 In order to compare occurrence and concentration of FIB and stanols with time, regressions 220 were performed by plotting average concentrations of each stanol against average 221 concentrations of FIB. Regression lines were drawn between four or several time points. The 222 regression coefficient $R^{2}$ values illustrate the relationship between the two variables compared.

\subsection{Statistical analysis}

\subsubsection{Decay rates distribution}

227 The validity of parametric tests is limited to samples following a normal distribution. When the distribution is unknown non parametric tests should be preferred. To infer on normality, a large number of samples is required, therefore to check whether the decay rates obtained in this study were normally distributed, we performed an additional experiment where 20

231 microcosms were investigated. These latter consisted of 2 L-polypropylene bottles placed in

232 the same conditions as in the study, filled with the same freshwater and the same pig manure 233 added to 1:100. For practical and economical reasons, only, culturable $E$. coli concentrations 234 were measured. The concentrations of cEC were followed every week for 6 weeks. Decay 235 constants $k 1$ and $k 2$ were found to be normally distributed with the Normality tests from 
236 XLSTAT $2010.4(\mathrm{n}=20)$ (data not shown). As a result parametric tests were performed to

237 compare decay constants of FIB and microbial markers. However, regression coefficients $R^{2}$ 238 were found not to follow a normal distribution, hence all $R^{2}$ were compared with the Mann 239 and Whitney test.

\subsubsection{Tests of significance}

242 Two null hypotheses were posed (i) no difference exists between decay rates of one target in 243 either treatments, (ii) no difference exists between decay rates of either indicator (cEC or cENT) and marker in a particular treatment (seawater or freshwater). The risk $\alpha$ to reject the null hypothesis while it might be true was set at 0.05 .

246 All statistical analyses were calculated from the regression coefficients $\left(R^{2}\right)$ and decay rates

$247(k)$ of three independent experimental replicates. Concerning microbial markers, an F-test was 248 performed to determine variance equality between set of samples prior to a two tailed 249 Student's $t$-test assuming equal or unequal variance depending on the F-test results. Analyses 250 were achieved by Microsoft Office Excel 2003.

251 It was not possible to compare decay rates from FIB and faecal stanols because the former 252 decay was described with a non linear regression model whilst the latter with a linear model.

253 Only the first null hypothesis could be considered. The distribution of stanols decay rates 254 could not be determined. As a consequence, to compare decay rates of stanols in freshwater 255 and seawater microcosms; a non parametric test for small samples of unknown distribution 256 (Mann-Whitney) was performed on XLSTAT 2010.4.

257 Decay rates were compared only if the $R^{2}$ of the linear regressions they originated from were 258 not statistically different. Otherwise, the test is stated to be non applicable (NA).

\section{RESULTS}


261 In this study, we examined the persistence of pig faecal markers in three independent

262 controlled unfiltered water microcosms under aerobic condition. Temperature oscillated

263 between 16 and $20{ }^{\circ} \mathrm{C}$ and dissolved $\mathrm{O}_{2}$ ranged from 8.3 to $9.7 \mathrm{mg} / \mathrm{L}$. The waters used to 264 constitute microcosms were free or slightly contaminated with FIB and stanols. In the 265 seawater, FIB were not detected. Among stanols, only coprostanol and sitostanol were 266 quantifiable with a concentration of 0.02 and $0.05 \mu \mathrm{g} / \mathrm{L}$, respectively. In the freshwater, cEC

267 concentration was $60 \mathrm{CFU} / 100 \mathrm{~mL}$ and cENT were not detected. The concentrations of 268 coprostanol, epicoprostanol, 24-ethylcoprostanol and sitostanol were 0.04, 0.02, 0.02 and 0.07 $269 \mu \mathrm{g} / \mathrm{L}$, respectively whereas campestanol was not detected. Pig-specific DNA markers Pig-2-

270 Bac and L. amylovorus were not detected in both types of water. At the end of the experiment 271 FIB were not detected in both types of water controls in $100 \mathrm{~mL}$. We thus inferred that 272 microflora and stanols present in the microcosms at day 0 arose from the pig manure.

274 3.1. Decay curves

\section{$275 \quad 3.1 .1$ FIB and microbial markers}

276 FIB and microbial markers followed a biphasic first order decay kinetic (Fig. 1). We, 277 therefore, used the Cerf biphasic decay model to determine the decay rates of the first and 278 second phase. An example of this model, illustrated by the behaviour of cENT in seawater is 279 shown on Fig. A.2. The model shows a sharper slope for the regression of the first phase than 280 for the second phase. Hence $k 1$ is always higher than $k 2$ in this model (Table 1). All decay 281 curves fitted to the model $\left(\mathrm{R}^{2}>0.90\right)$. As indicated by the value of the $\mathrm{f}$ parameter 282 proportion of the initial concentration of the target that declined during the first phase-, more 283 than $97 \%$ of the initial inoculum was lost during this phase. The decimal reduction time 284 occurred thus during the first phase soon after the beginning of the experiment and was 285 reached in less than 6 days independently of the bacteria or the microcosm conditions. 286 However, in many instances a small remaining proportion persisted until the end of the 
experiment. Culturable E. coli were recovered until day 20 in seawater whilst it was still

288 detected on day 55 in freshwater microcosms. Culturable enterococci and L. amylovorus

289 concentrations were over the limit of quantification in both types of water on the last day of

290 the experiment. In seawater, Pig-2-Bac marker followed the same trend as E. coli, it reached

291 the quantification limit by day 13. On day 20, it was detected just below quantification limit

292 in the three microcosms. It was decided to take this point into account for calculations (Fig.

293 A.1). The week after Pig-2-Bac was still detected in two microcosms. In freshwater, it was

294 found over quantification limit until day 27 in the three microcosms (Fig. B.1), but remained 295 detectable until day 34 in two microcosms.

\subsubsection{Faecal stanols}

298 Faecal stanols followed a monophasic first order decay kinetic as illustrated by Fig. B.2. In 299 seawater microcosms, initial concentrations of coprostanol, episcoprostanol, 24300 ethylcoprostanol, campestanol and sitostanol were 16.7, 3.1, 12.1, 2.6 and $4.7 \mu \mathrm{g} / \mathrm{L}$, 301 respectively. Their final concentrations reached $0.15,0.05,0.18,0.03$ and $0.10 \mu \mathrm{g} / \mathrm{L}$, 302 respectively (Fig A.3). The concentrations observed after 55 days represented a degradation 303 of 98 to $99 \%$ of the initial amounts of the five stanols. Nevertheless, they remained higher 304 than the initial concentrations in seawater before the addition of pig manure. In freshwater 305 microcosms, initial concentrations of coprostanol, epicoprostanol, 24-ethylcoprostanol, 306 campestanol and sitostanol were higher than in seawater microcosms and were 33.4, 9.3, 25.5, 3076.9 and $11.8 \mu \mathrm{g} / \mathrm{L}$, respectively whereas their final concentrations were $0.49,0.15,0.53,0.10$ 308 and $0.20 \mu \mathrm{g} / \mathrm{L}$, respectively. At the end of the experiment, they were in average $13 \pm 6$ times 309 higher than the initial concentrations in freshwater before the addition of pig manure. 310 Furthermore, as observed in the seawater microcosms, they represented a degradation of 98 to $31199 \%$ of the initial amount of the five stanols (Fig. B.3). 


\subsection{Progression of stanol ratios}

314 At the beginning of the experiment, the initial values of $\mathrm{R}_{1}$ (coprostanol/ (coprostanol +24 -

315 ethylcoprostanol)) and $\mathrm{R}_{2}$ (sitostanol/coprostanol) ratios ranged between 0.57 and 0.58 and

316 between 0.20 and 0.23 , respectively. Regardless the microcosms, the ratio $\mathrm{R}_{1}$ progressively

317 decreased to reach a value of 0.47 (Fig. A.4), due to the difference of decay rate between

318 coprostanol and 24-ethylcoprostanol (Table 1). The changes in the values of $\mathrm{R}_{2}$ were also

319 similar in freshwater and in seawater. They were most marked than those of $R_{1}$ ratio as $R_{2}$

320 ranged mainly from 0.20 to 0.91 with however a maximum value of 1.55 on day 20 (Fig.

321 B.4).

322

323 3.3. Decay rates statistical analysis

\section{3.3.1. Decay rates comparisons from seawater and freshwater microcosms}

325 The regression coefficients from non linear regressions were not statistically different. As a 326 consequence every $k 1$ and $k 2$ drawn from microbial markers kinetic models could be compared. The results concerning the first null hypothesis are shown in Table 1. $L$. amylovorus decay first constants $(k 1)$ were statistically different whilst their seconds $(k 2)$ were not. The opposite was noted for Pig-2-Bac, its first decay constant was not different in

330 seawater or freshwater microcosms whilst they were significantly different during the second 331 phase.

332 For stanols, the regression coefficients from linear regressions were also not statistically 333 different. Thus, every $k$ drawn from faecal stanols kinetics could be compared. According to 334 the Mann and Whitney non parametric test, stanols decay rates were not significantly different 335 in freshwater or seawater microcosms (Table 1).

336 
338 In seawater, the first phase constant from Pig-2-Bac decay did not significantly differed from

339 that of FIB. Contrary to this pig-specific marker, the decrease of L. amylovorus was slower

340 than the ones of cEC $(p<0.0001)$ and of cENT $(p=0.027)$ during the first phase. During the

341 second phase, the decays of both genetic markers were not significantly different from that of

342 cENT whilst they were lower than that of $\mathrm{cEC}(p<0.001)$. In freshwater, Pig-2-Bac and $L$.

343 amylovorus decays did not significantly differed from that of cENT in the first phase while

344 they were faster than $\mathrm{cEC}(p=0.001)$. During the second phase, decay rates of both markers

345 were not statistically different from those of FIB.

\subsection{Regression tests}

348 In seawater microcosms, the changes in concentrations of $\mathrm{cEC}$ from day 0 to day 13 were

349 well correlated with those of coprostanol $\left(R^{2}=0.92\right)$ and 24-ethylcoprostanol $\left(R^{2}=0.91\right)$.

350 However the decrease in concentrations of $\mathrm{cEC}$ was not correlated to concentrations of epicoprostanol, campestanol and sitostanol $\left(R^{2}<0.40\right)$ due to their increases between day 6 and day 13. The correlation between the decrease of concentrations of cENT and stanols showed a same trend with $R^{2}>0.95$ for coprostanol and 24-ethylcoprostanol and $R^{2}<0.60$ for epicoprostanol, campestanol and sitostanol. In freshwater microcosms, the five stanols were better correlated to the change in concentrations of cEC $\left(R^{2}>0.85\right)$ than to cENT with $R^{2}$ ranging from 0.73 (sitostanol) to 0.78 (epicoprostanol).

\section{DISCUSSION}

359 The objective of this research was to evaluate the persistence of bacterial and chemical

360 markers as compared to the survival of indicator organisms that are measured currently to assess water microbial quality. It is expected that a microbial load added to a water body by a

362 faecal pollution for instance would decline with time due to the effects of several parameters 363 including sunlight, sedimentation, dilution, transport or grazing by biological agents (Barcina 
et al., 1997; Easton et al., 1999). Although here, conditions of natural water bodies were not

365 fulfilled, since the experiment was performed in a closed environment, a decline was

366 observed for every target: molecular and living organisms. This observation is consistent with

367 other recent microcosm studies in freshwater and seawater (Dick et al., 2010; Walters et al., 368 2009).

\subsection{Decay curves}

371 The kinetics of the FIB and microbial markers followed a biphasic curve (Fig. 1). The first 372 phase occurred within 6 days on average. During this phase, a high proportion of the starting inoculum decayed. The remaining proportion persisted in the water column and seemed to be

374 more resistant to decline, since the second phase decline was slow or even null. This was 375 reported before by Easton et al. (1999) who showed, using in-situ chambers that faecal 376 microorganisms did not die-off at a constant rate, and this was only true for the initial decline.

377 Their experiment demonstrated that the die-off rate slowed down as the organism level 378 approached equilibrium with the environment. They found that the initial rapid die-off 379 occurred, generally during the first seven days of the experiment which is consistent with our 380 findings. They proposed two hypotheses to explain this observation (1) the microorganism 381 die-off at a rapid rate until the carrying capacity of the environment is reached, (2) 382 microorganisms would use quorum sensing to regulate their numbers and adapt to their new 383 environment. Although here other parameters than the genetic programming of organisms 384 might have triggered the decline such as sedimentation (Hartz et al., 2008), grazing by 385 protozoa (Bell et al., 2009) or loss of culturability (Barcina et al., 1997), it seems that bacteria 386 can regulate their numbers in a microcosm. Thus, Hellweger et al. (2009) established the 387 biphasic decay kinetic of a pure strain of culturable E. coli inoculated in sterile phosphate 388 buffered saline. They observed a decline of the initial inoculum during two days followed by 389 a slight increase of $E$. coli densities. Their experiment established that the resistant fraction 
was not a population or strain dependent parameter since they used a pure strain. They

391 proposed as possible explanation that this resistant fraction was made of mutants growing on

392 nutrients released by dead cells.

393 In agreement with our results, Bae and Wuertz (2009) demonstrated the biphasic persistence 394 of Bacteroidales gene markers and Enterococcus 23S rRNA gene from human, cattle and dog 395 faecal samples in seawater. Furthermore, Dick et al. (2010) also observed a decay with a 396 biphasic pattern for cEC and Bacteroidales genetic markers from human wastewater in 397 freshwater. They also noted that $99 \%$ of the initial inoculum was inactivated during the first 398 phase regardless the microcosm conditions. It is noteworthy that in the mentioned studies, 399 although the type of water, the polluting matrix and the physical conditions differed, the 400 biphasic pattern of every different microbial target was observed. This is consistent with our 401 results as each bacterial target in both treatments followed a biphasic decay trend.

402 Furthermore, it has been reported that a high level of prey would be reduced by predators to 403 an equilibrium density that would ensure the survival of the predators (Marino and Gannon, 1991; Menon et al., 2003). It appears that numerous factors are involved in the biphasic decay and the mechanisms responsible for this trend. Results from our study would probably depend

406 on both predation, as the waters were not filtered, and on intrinsic characteristic of the studied 407 bacteria.

408 The persistence pattern of the DNA markers tended to follow the survival pattern of the living 409 organisms. We could then speculate that the DNA we quantified arose from living cells. This 410 is somehow illustrated by the positive second decay rate from the L. amylovorus marker 411 (Table 1). This very low rate could be due to sampling or measurement variations or to a 412 multiplication of the marker. However, it was not possible to verify this hypothesis because 413 no medium enables the isolation of L. amylovorus from a complex matrix.

414 Stanol decay results were concordant with the evolution of coprostanol in seawater during 415 microcosm experiment performed in darkness at $19^{\circ} \mathrm{C}$ (Thoumelin et al., 1990). The increase 
416 of the concentration of sitostanol, campestanol and epicoprostanol between day 6 and day 13

417 could be due to the death of living organisms inherited from the pig manure. As a

418 consequence the sterols that constitute those organisms were liberated in the dissolved phase

419 (Marty et al., 1996) and further hydrogenated into sitostanol, campestanol and epicoprostanol

420 (Pratt et al., 2008). This explanation would agree with the observed microbial decay.

\subsection{FIB survival and markers persistence}

423 In seawater, Pig-2-Bac presented a rapid decay rate close to that of cEC (1.1 and $1.3 \mathrm{~d}^{-1}$, 424 respectively) during the first phase, twice faster than that of cENT. It has been described that protozoa eliminate gram positive bacteria at lower rates than gram negative bacteria (Barcina et al., 1997; Davies et al., 1995). Furthermore, in a recent study Balleste and Blanch (2010) proved that Bacteroides fragilis survival was highly hindered by grazing predators in warm conditions in a river. Additionally, Jin et al. (2005) established in a natural slightly salted water storm event experiment that the percentage of $E$. coli attached to suspended particles was 21.8 to $30.4 \%$ compared to 8.3 to $11.5 \%$ for enterococci. However, in salty water, Gram positive bacteria would try to protect themselves from the osmotic pressure by attaching to organic matter (Hartz et al., 2008). In this experiment, turbidity was not measured, but it was clear since we could filtered the water from day 13 , that suspended organic matter had settled and thus the water column was poorer in organic matter from that day. As a consequence, the concentration of organic matter might have accounted for in the survival of E. coli and Pig-2Bac marker in seawater. Predation and sedimentation might explain the more rapid decay of

437 Gram negative compared to Gram positive markers in seawater. Another factor that might 438 explain the sensibility of the Bacteroidales marker compared to the three other organisms in 439 freshwater, is their sensibility to oxygen. It is well established that Bacteroidales cells are 440 negatively affected by increased dissolved oxygen in water (Bae and Wuertz, 2009; Balleste 441 and Blanch, 2010). In freshwater, the Bacteroidales marker was the only target not detected 
until the end of the experiment although, Pig-2-Bac decay constant was not different from

443 cENT decay constants (Table 1), thus the shorter relative persistence time period might also 444 be explained by the higher detection limit of the method. This could be improved by filtering 445 higher volumes of water especially, this would be possible in natural environment normally 446 less concentrated in suspended organic matter, or improving DNA extraction yield.

447 No microcosm studies have yet reported on the persistence of L. amylovorus. It is thus 448 interesting to note that the pig-specific L. amylovorus marker followed the same trend as 449 cENT until day 55 in seawater and in freshwater, although the detection limit was elevated 450 (112 CFU equivalent/100 mL) compared to that of FIB (1 CFU/100 mL). However, the marker follows cEC evolution only in freshwater as it was inactivated more rapidly in seawater. This is not surprising as it has been demonstrated that unlike Enterococcus faecalis or Lactobacillus casei, E. coli does not harbour resistance mechanisms to high osmotic pressure (Lee et al., 1977). However, as stated before, attachment to organic matter aids the bacteria to resist to this pressure.

The progressions of the amount of FIB and of the concentration of stanols followed the same trends except for cEC in seawater. Coprostanol and ethylcoprostanol were correlated with cEC until it was no more detected in seawater. Regression coefficients were higher between

459 the five stanols and cENT than with cEC in seawater. On the other hand in freshwater 460 microcosms the five stanols concentrations were more closely related to the amount of cEC than of cENT. However the regression coefficients were still high i.e. $R^{2}>0.70$ and defined a close relationship between the occurrence and concentrations of stanols and FIB.

\section{4.3. Effect of the type of water}

465 To determine whether the type of water influenced the persistence of markers in the conditions of the experiment, we compared decay rates observed from both microcosms for each target. Pig-2-Bac was not significantly influenced by the type of water during the first 
468 phase maybe due to the presence of suspended particles but salinity or other factors from the

469 seawater accelerated the decay during the second phase (Table 1) when the particles had

470 settled. As a consequence, the marker was detected one more week in freshwater microcosms.

471 These results are somehow different from those from Okabe and Shimazu (2007) who

472 exposed their Bacteroidales pig marker Pig-Bac2 to different salinities and observed no real

473 difference in the persistence or decay of the marker to $0,10,20$ and $30 \mathrm{~g} / \mathrm{L}$ under dark

474 conditions; however their experiments were performed at $10^{\circ} \mathrm{C}$ which decreases the decay.

475 The lactobacillus marker was affected by the type of water at the beginning of the experiment,

476 but the remaining proportion of the population was not affected and persisted for the same

477 length of time in freshwater and seawater microcosms. It has been shown that L. amylovorus

478 can multiply in $\mathrm{NaCl}$ concentration of 5-10 g/L and can survive in concentrations from 20 to

$47940 \mathrm{~g} / \mathrm{L}$ (Neysens et al., 2003). This new genetic marker, which belongs to a genus

480 phylogenetically close to the Enterococcus genus, might be useful to monitor marine waters.

481 The concentrations of stanols after the addition of pig manure were twice to three times

482 higher in the dissolved phase $(<0.7 \mu \mathrm{m})$ of freshwater than of seawater. This observation was

483 probably due to the increased salinity in seawater that induced an aggregation of dissolved

484 macromolecules instead of allowing them to suspend in the dissolved phase as colloids. In

485 spite of slight differences observed on decay curves (Fig. 3), the decay rates calculated for

486 stanols in seawater and freshwater microcosms did not exhibit significant differences (Table 487 1).

489 4.4. MST toolbox validation

490 Pig-2-Bac and L. amylovorus markers were selected to be part of a toolbox to identify sources 491 of faecal pollution in water in our previous study (Gourmelon et al., 2010), we wanted to 492 estimate how their detection is representative of a faecal load. In seawater and freshwater, in 493 the conditions of the study, according to the concentrations in culturable enterococci, the 
494 faecal contamination was present until the end of the experiment. L. amylovorus followed

495 globally the same trend as cENT and its detection was thus representative of the faecal load

496 during two months. Pig-2-Bac followed also the same trend as cENT but only until day 20

497 and day 27 in seawater and freshwater, respectively. Thus it was no longer detected whilst the

498 faecal contamination was still present. However, although Pig-2-Bac appeared less persistent

499 than L. amylovorus, both markers were detected for a long period of time (at least 20 days)

500 that would allow water managers to take necessary actions in cases of important discharges.

501 The development of the MST toolbox in our previous study has highlighted two ratios

502 allowing the discrimination between human, pig and cow faeces. Thus, coprostanol to the sum

503 of coprostanol and 24-ethylcoprostanol $\left(\mathrm{R}_{1}\right)$ allows the differentiation between human (>

$5040.71)$, porcine $(0.55-0.59)$ and herbivore $(<0.41)$ contributions and the second ratio, sitostanol

505 to coprostanol $\left(\mathrm{R}_{2}\right)$ exhibits values $>1$ for bovine manures and $<0.4$ for pig manures and

506 waste water treatment plant effluents (Gourmelon et al., 2010). In seawater and freshwater

507 microcosms, between day 0 and day $13, \mathrm{R}_{1}$ exhibited values characteristic of pig manure.

508 However, over the course of the experiment, $\mathrm{R}_{1}$ remained above the specific values of bovine

509 manure, suggesting that slight changes in $\mathrm{R}_{1}$ values over time do not lead to misinterpretation

510 of the origin of the contamination. In both microcosms, $\mathrm{R}_{2}$ was characteristic of pig manure

511 from day 0 to day 6 . As a consequence, the combination of stanol ratios $R_{1}$ and $R_{2}$ can be

512 investigated in order to indicate a faecal contamination from pig manure up to six days from

513 the beginning of the discharge, which allows time to enumerate FIB in order to determine if

514 further analyses are necessary.

515

\section{5. CONCLUSION}

517 This laboratory microcosm study aimed to compare the decay rates of FIB, Bacteroidales Pig-

518 2-Bac and L. amylovorus pig genetic markers and stanol ratios in both freshwater and 519 seawater inoculated with pig manure. 
520 Regardless the microcosm conditions and the target, the persistence or survival profiles of the

521 two genetic markers and of the FIB followed a biphasic curve whereas the five stanols

522 followed a monophasic first order decay kinetic.

523 The persistence of genetic and chemical markers were similar in freshwater and in seawater.

524 According to the values of the ratio $\mathrm{R}_{1}$ and $\mathrm{R}_{2}$, and as the persistence of $L$. amylovorus and

525 Pig-2-Bac Bacteroidales marker was relatively close to that of cultivable E. coli and

526 enterococci, all these markers can be used to complement E. coli and enterococcus detection

527 method to identify a source of pig pollution at least during 6 days when the time point of the

528 contaminating discharge is known. Furthermore, they should prove useful to trace a pig faecal

529 pollution from bathing areas and shellfish farming waters that are sporadically classified as

530 "non satisfactory" in terms of microbial quality.

531

\section{AKNOWLEDGEMENT}

533 This work was done in a French project entitled Marquopoleau, recognised by the economic 534 competitiveness cluster Pôle Mer Bretagne and supported by the Fond Unique 535 Interministeriel, Regional council of Brittany, County council of Morbihan, County council of 536 Finistère and Brest Métropole Océane.

537 The authors wish to thank Emmanuelle Guillerm from IDHESA Bretagne Océane for her 538 technical assistance.

\section{REFERENCES}

541 Bae, S. and Wuertz, S. (2009) Rapid decay of host-specific faecal Bacteroidales cells in 542 seawater as measured by quantitative PCR with propidium monoazide. Water Research $43,4850-4859$. 
544 Balleste, E. and Blanch, A. R. (2010) Persistence of Bacteroides Species Populations in a River as Measured by Molecular and Culture Techniques. Applied and Environmental Microbiology 76, 7608-7616.

Balleste, E., Bonjoch, X., Belanche, L.A. and Blanch, A.R. (2010) Molecular Indicators Used in the Development of Predictive Models for Microbial Source Tracking. Applied and Environmental Microbiology 76, 1789-1795.

Barcina, I., Lebaron, P., VivesRego, J. (1997) Survival of allochthonous bacteria in aquatic systems: A biological approach. FEMS Microbiology Ecology 23, 1-9.

Bell, A., Layton, A. C., Mckay, L., Williams, D., Gentry, R., Sayler, G. S. (2009) Factors Influencing the Persistence of Fecal Bacteroides in Stream Water. Journal of Environmental Quality 38, 1224-1232.

Davies, C. M., Long, J. A. H., Donald, M., Ashbolt, N. J. (1995) Survival of Fecal Microorganisms in Marine and Fresh-Water Sediments. Applied and Environmental Microbiology 61, 1888-1896.

Dick, L.K., Bernhard, A.E., Brodeur, T.J., Domingo, J.W.S., Simpson, J.M., Walters, S.P. and Field, K.G. (2005) Host distributions of uncultivated faecal Bacteroidales bacteria reveal genetic markers for faecal source identification. Applied and Environmental

Dick, L.K., Stelzer, E.A., Bertke, E.E., Fong, D.L. and Stoeckel, D.M. (2010) Relative Decay of Bacteroidales Microbial Source Tracking Markers and Cultivated Escherichia coli in Freshwater Microcosms. Applied and Environmental Microbiology 76, 3255-3262.

565 Easton, J. H., Lalor, M., Gauthier, J. J., Pitt, R., Newman, D. E., Meyland, S. (1999) 566 Determination of Survival Rates for Selected Bacterial and Protozoan Pathogens from Wet Weather Discharges. WEFTEC 1999. Water Environment Federation 72nd Annual Conference and Exposition. New Orleans. 
Field, K. G. and Samadpour, M. (2007) Fecal source tracking, the indicator paradigm, and managing water quality. Water Research 41, 3517-38.

571

572

573

574

575

576

577

578

579

580

581

582

583

584

585

586

587

588

589

590

591

592

Gourmelon, M., Caprais, M.P., Mieszkin, S., Marti, R., Wéry, N., Jardé, E., Derrien, M., Jadas-Hecart, A., Communal, P.Y., Jaffrezic, A. and Pourcher, A.M. (2010) Development of microbial and chemical MST tools to identify the origin of the faecal pollution in bathing and shellfish harvesting waters in France. Water Research 44, 4812-4824.

Hartz, A., Cuvelier, M., Nowosielski, K., Bonilla, T. D., Green, M., Esiobu, N., McCorquodale, D. S., Rogerson, A. (2008) Survival potential of Escherichia coli and enterococci in subtropical beach sand: Implications for water quality managers. Journal of Environmental Quality 37, 898-905.

Hellweger, F.L., Bucci, V., Litman, M.R., Gu, A.Z. and Onnis-Hayden, A. (2009) Biphasic Decay Kinetics of Faecal Bacteria in Surface Water Not a Density Effect. Journal of Environmental Engineering-Asce 135, 372-376.

Jarde, E., Gruau, G. and Jaffrezic, A. (2009) Tracing and Quantifying Sources of Fatty Acids and Steroids in Amended Cultivated Soils. Journal of Agricultural and Food Chemistry $57,6950-6956$.

Jeanneau, L., Jarde, E., Gruau, G. (2011) Influence of salinity and natural organic matter on the solid phase extraction of sterols and stanols: Application to the determination of the human sterol fingerprint in aqueous matrices. Journal of Chromatography A 1218, 25132520.

Jin, G., Jeng, H. W., Bradford, H., Englande, A. J. (2005) Comparison of E. coli, Enterococci, and fecal coliform as indicators for brackish water quality assessment (vol 76, pg 245, 2004). Water Environment. Research. 77, 433-433. 
593 Konstantinov, S.R., Smidt, H. and de Vos, W.M. (2005) Representational difference analysis and real-time PCR for strain-specific quantification of Lactobacillus sobrius sp nov. Applied and Environmental Microbiology 71, 7578-7581.

Lee, D.U., Heinz, V. and Knorr, D. (2001) Biphasic inactivation kinetics of Escherichia coli in liquid whole egg by high hydrostatic pressure treatments. Biotechnology progress 17, 1020-1025.

Lee, S.K., Calcott, P.H. and MacLeod, R.A. (1977) Relationship of cytochrome content to the sensitivity of bacteria to $\mathrm{NaCl}$ on freezing and thawing. Canadian journal of microbiology 23, 413-419.

Leeming, R., Ball, A., Ashbolt, N. and Nichols, P. (1996) Using faecal sterols from humans and animals to distinguish faecal pollution in receiving waters. Water Research 30,

Marino, R. P. and Gannon, J. J. (1991) Survival of faecal coliforms and faecal streptococci in 606 storm drain sediment. Water Research 25, 1089-1098.

607

Marti, R., Dabert, P., Ziebal, C. and Pourcher, A.M. (2010) Evaluation of Lactobacillus 608 sobrius/L-amylovorus as a New Microbial Marker of Pig Manure. Applied and Environmental Microbiology 76, 1456-1461.

Marty, Y., Quemeneur, M., Aminot, A., LeCorre, P. (1996) Laboratory study on degradation of fatty acids and sterols from urban wastes in seawater. Water Research 30, 1127-1136.

612 Menon, P., Billen, G., Servais, P. (2003) Mortality rates of autochthonous and fecal bacteria in natural aquatic ecosystems. Water Research. 37, 4151-4158.

614 Mieszkin, S., Furet, J.P., Corthier, G. and Gourmelon, M. (2009) Estimation of Pig Faecal 615 Contamination in a River Catchment by Real-Time PCR Using Two Pig-Specific 616 Bacteroidales 16S rRNA Genetic Markers. Applied and Environmental Microbiology 617 $75,3045-3054$. 
618 Neysens, P., Messens, W. and De Vuyst, L. (2003) Effect of sodium chloride on growth and 619 bacteriocin production by Lactobacillus amylovorus DCE 471. International Journal of $620 \quad$ Food Microbiology 88, 29-39.

621 Okabe, S. and Shimazu, Y. (2007) Persistence of host-specific Bacteroides-Prevotella 16S 622 rRNA genetic markers in environmental waters: effects of temperature and salinity. Applied Microbiology and Biotechnology 76, 935-944.

624 Pratt, C., Warnken, J., Leeming, R., Arthur, J. M., Grice, D. I. (2008) Degradation and responses of coprostanol and selected sterol biomarkers in sediments to a simulated major sewage pollution event: A microcosm experiment under sub-tropical estuarine conditions. Organic Geochemistry 39, 353-369.

Shah, V.G., Dunstan, R.H., Geary, P.M., Coombes, P., Roberts, M.K. and Von NagyFelsobuki, E. (2007) Evaluating potential applications of faecal sterols in distinguishing sources of faecal contamination from mixed faecal samples. Water Research 41, 36913700 .

Soller, J.A., Schoen, M.E., Bartrand, T., Ravenscroft, J.E. and Ashbolt, N.J. (2010) Estimated human health risks from exposure to recreational waters impacted by human and nonhuman sources of faecal contamination. Water Research 44, 4674-91.

Thoumelin, G., Marty, Y., Lecorre, P. and Aminot, A. (1990) Laboratory Investigation of the Degradation of Organic-Matter in Estuarine and Coastal Waters - Sterols Variations. Oceanologica Acta 13, 53-60.

Thurston-Enriquez, J.A., Gilley, J.E. and Eghball, B. (2005) Microbial quality of runoff

Tyagi, P., Edwards, D. R., Coyne, M. S. (2009) Fecal Sterol and Bile Acid Biomarkers: following land application of cattle manure and swine slurry. Journal of Water and Pollution 198, 45-54. 
644 Ufnar, J.A., Ufnar, D.F., Wang, S.Y. and Ellender, R.D. (2007) Development of a swine645 specific faecal pollution marker based on host differences in methanogen morA genes. $646 \quad$ Applied and Environmental Microbiology 73, 5209-5217.

647 Walters, S.P., Yamahara, K.M. and Boehm, A.B. (2009) Persistence of nucleic acid markers 648 of health-relevant organisms in seawater microcosms: Implications for their use in 649 assessing risk in recreational waters. Water Research 43, 4929-4939. 


\section{Figures Captions:}

651

652 Fig. 1 - Decay curves of pig specific microbial markers in water microcosms seeded with 653 liquid pig manure (1:100 dilution), (A) seawater, (B) freshwater. Conditions: dark, $\mathrm{O}_{2}$ 654 saturation, around $18{ }^{\circ} \mathrm{C}$. The uncertainties represent standard errors. Limit of quantification 655 was 1 CFU/100 mL for FIB, 1250 gene copies/100 mL for Pig-2-Bac and $112 \mathrm{CFU}$ 656 equivalent/100 $\mathrm{mL}$ for L. amylovorus.

657

658 Fig. 2 - Modelisation of the mean concentration of cENT (A) by Cerf biphasic decay model $659\left(R^{2}=0.97\right)$ and of 24-ethylcoprostanol $(\mathrm{B})$ by Chick first order decay model $\left(R^{2}=0.98\right)$ from 660 the seawater microcosms

661

662 Fig. 3 - Decay curves of stanols in seawater (A) and freshwater (B) microcosms. The 663 uncertainties represent standard errors. The scale of Y-axes are different

664

665 Fig. 4 - Evolution of stanols ratios $\mathrm{R}_{1}$ (A; coprostanol/coprostanol+24-ethylcoprostanol) and $666 \mathrm{R}_{2}$ (B; sitostanol/coprostanol). Grey areas correspond to the range of values characteristic of 667 pig manure. SWP: seawater, FWP: freshwater.

668

669 
670
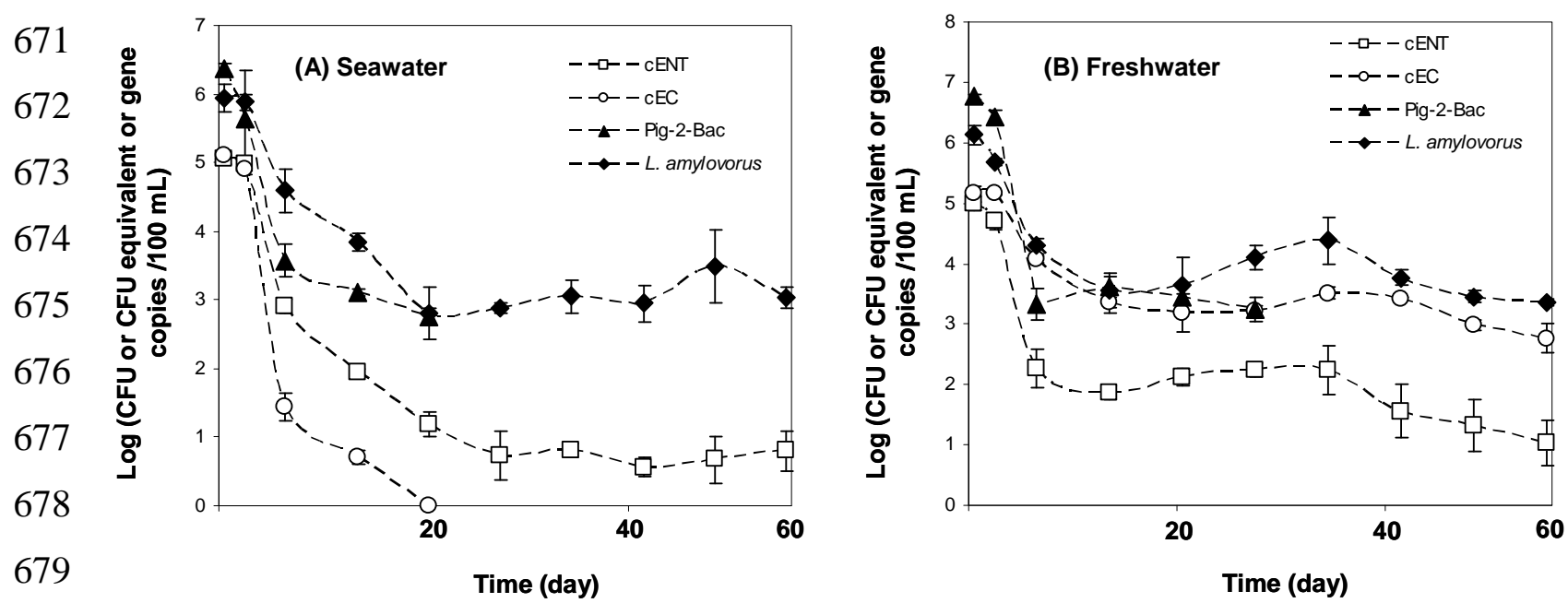

$680 \quad$ Fig 1

681

682

683 Time (day)

684

685

686

687

688

689

690

691

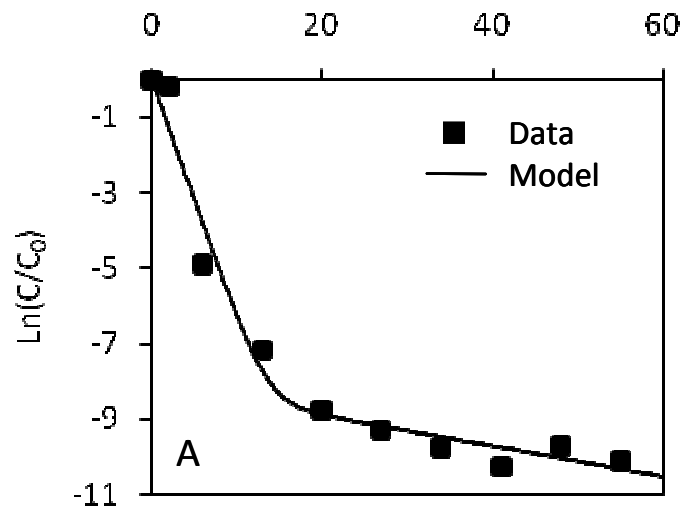

Time (day)

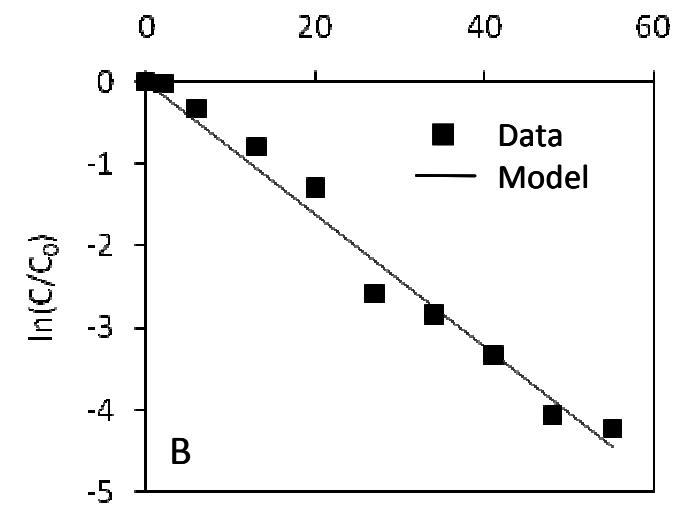

692 Fig 2

693

694

695

696

697

698

699

700

701

702

703 
705

706

707

708

709

710

711

712

713

714

715

716

717

$718 \quad$ Fig 3

719

720

721

722

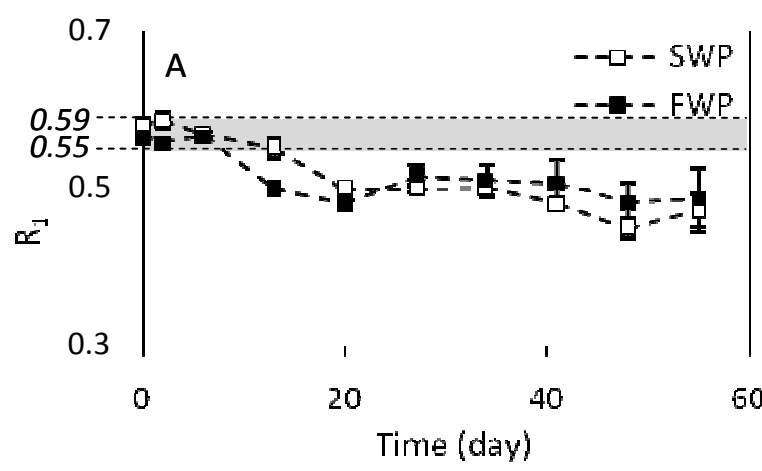

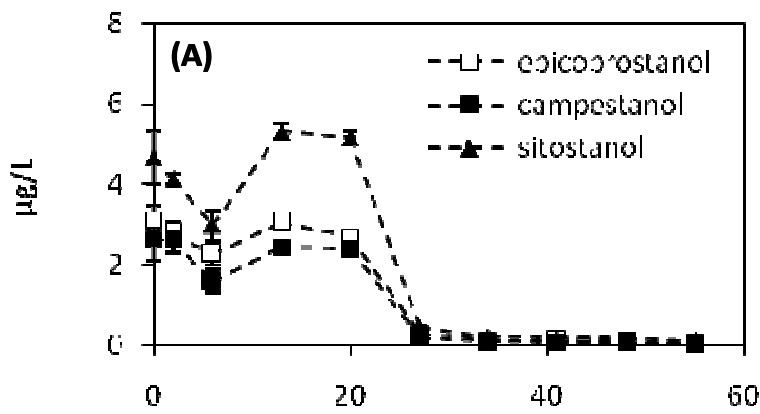

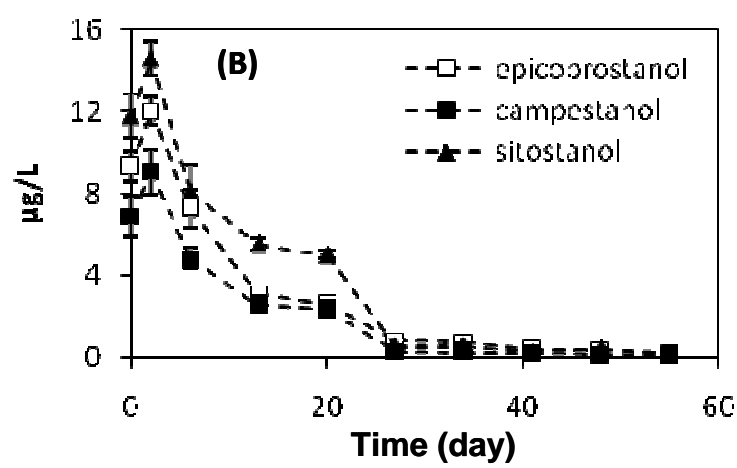

723

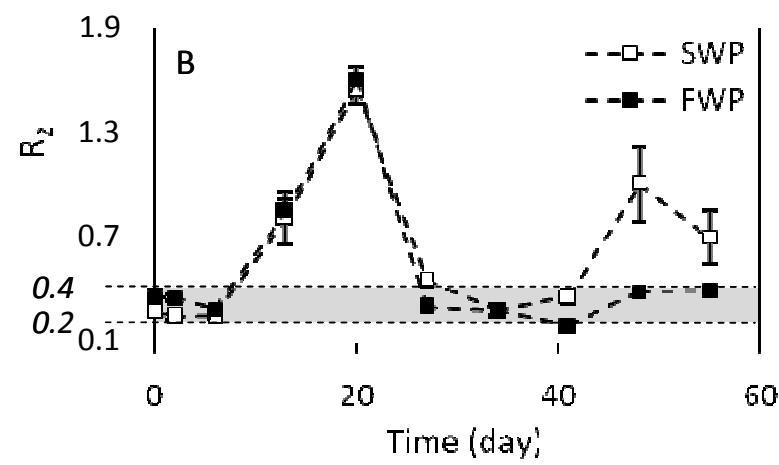

$724 \quad$ Fig4 
725 Table 1 - Decay rates and T90 of FIB and pig specific microbial and chemical markers in water microcosms seeded with liquid pig manure (1:100 dilution). p-values represent comparison between decay rates in seawater and freshwater. Conditions: dark, $\mathrm{O}_{2}$ saturation, around $18{ }^{\circ} \mathrm{C}$.

\begin{tabular}{|c|c|c|c|c|c|c|c|c|c|c|c|c|}
\hline \multirow[b]{2}{*}{ Marker } & \multicolumn{5}{|c|}{ Seawater } & \multicolumn{5}{|c|}{ Freshwater } & \multirow[b]{2}{*}{$\begin{array}{c}p \text {-value } \\
k 1\end{array}$} & \multirow[b]{2}{*}{$\begin{array}{c}p \text {-value } \\
k 2\end{array}$} \\
\hline & $k 1\left(d^{-1}\right)$ & $k 2\left(d^{-1}\right)$ & $f(\%)$ & $T_{90}$ (d) & $R^{2}$ & $k 1\left(d^{-1}\right)$ & $k 2\left(d^{-1}\right)$ & $f(\%)$ & $\mathrm{T}_{90}(\mathrm{~d})$ & $R^{2}$ & & \\
\hline cE. coli & 1.291 & 0.388 & 99.7 & 1.8 & 0.96 & 0.428 & -0.021 & 97.8 & 5.4 & 0.94 & 0.0006 & 0.0004 \\
\hline cENT & 0.605 & 0.016 & 99.9 & 3.8 & 0.97 & 1.015 & -0.048 & 99.7 & 2.3 & 0.94 & 0.0377 & 0.6714 \\
\hline Pig-2-Bac & 1.100 & 0.075 & 99.9 & 2.1 & 0.99 & 1.247 & -0.001 & 99.9 & 1.9 & 0.95 & 0.7488 & 0.0412 \\
\hline L. amylovorus & 0.406 & -0.031 & 99.9 & 5.7 & 0.97 & 0.737 & -0.014 & 99.4 & 3.1 & 0.94 & 0.0295 & 0.3089 \\
\hline Coprostanol & 0,092 & & & 23.7 & 0.98 & 0,082 & & & 29.5 & 0.92 & 0,1000 & \\
\hline Ethylcoprostanol & 0,086 & & & 26.2 & 0.98 & 0,075 & & & 32.0 & 0.93 & 0,2000 & \\
\hline Epicoprostanol & 0,078 & & & 25.0 & 0.91 & 0,075 & & & 29.1 & 0.98 & 0,3000 & \\
\hline Campestanol & 0,078 & & & 25.6 & 0.88 & 0,083 & & & 25.6 & 0.93 & 1,0000 & \\
\hline Sitostanol & 0,072 & & & 32,0 & 0,82 & 0,079 & & & 29,1 & 0,91 & 0,3000 & \\
\hline
\end{tabular}


